\title{
APLIKASI SISTEM PEMANDU WISATA DI KOTA CIREBON BERBASIS ANDROID
}

\section{ANDROID BASED TOUR GUIDE APPLICATION SYSTEM IN CIREBON CITY}

\author{
Triyono Bentar Nugroho ${ }^{1}$, Muhammad Iqbal,ST,MT. ${ }^{2}$, Yuyun Siti Rohmah,ST,MT. ${ }^{3}$ \\ Prodi D3 Teknik Telekomunikasi, Fakultas Ilmu Terapan, Universitas Telkom \\ Jln. Telekomunikasi Dayeuhkolot Bandung 40257 Indonesia \\ 1triyonobentar@gmail.com, ${ }^{2}$ iqbal@ tass.telkomuniversity.ac.id, ${ }^{3}$ yuyunsr@tass.telkomuniversity.ac.id
}

\begin{abstract}
Abstrak
Cirebon merupakan kota yang mempunyai potensi pariwisata yang banyak dikunjungi wisatawan. Cirebon sangat kental dengan budaya islam jawa dengan dibuktikan bahwa Cirebon mempunyai 3 Keraton yaitu keraton Kacirebonan, Keraton Kesepuhan dan Keraton kanoman. Budaya yang dimiliki Kota Cirebon ini memberikan daya tarik yang berbeda bagi para wisatawan untuk berkunjung ke Kota Cirebon. Bagi wisatawan yang baru mengenal wilayah Kota Cirebon dirasa sangat menyulitkan dengan mendapatkan informasi dan data mengenai lokasi-lokasi yang ingin dikunjungi. Pemandu wisata dapat menjadi solusi bagi para wisatawan yang baru mengenal wilayah Cirebon agar dapat memberikan informasi-informasi umum yang dibutuhkan wisatawan tersebut, tetapi peranan pemandu wisatawan belum tentu dapat memenuhi kebutuhan maupun keinginan wisatawan tersebut.

Pada paper ini dirancang sebuah sistem aplikasi pemandu berbasis platform Android. Aplikasi ini dapat memberikan informasi dan menjadi penunjuk arah lokasi wisata yang ingin dituju. Aplikasi ini dapat berfungsi layaknya pemandu wisata dimana informasi-informasi yang diberikan mancakup data kuliner, tempat wisata, hotel, kesenian, tempat ibadah dan trasnportasi.

Hasil Keluaran dari aplikasi pemandu wisata ini adalah informasi tempat wisata dan penunjuk arah dengan akurasi A-GPS minimal error jarak 3 meter dan maksimal error 30 meter. Kecepatan aplikasi dalam menentukan posisi pengguna bergantung pada kuat sinyal jaringan dan keadaan kondisi sekitar. Dengan demikian aplikasi ini sudah dapat diimplementasikan pada smartphone android.
\end{abstract}

Kata kunci: pemandu wisata, platform android, Cirebon, smartphone.

\section{Abstract}

Cirebon is a city that has the potential of tourism visited by many tourists. Cirebon is very thick with the culture Javanese Islam has proved that 3 Cirebon Kraton Kraton is Kacirebonan, Kraton and Kraton Kanoman Kesepuhan . Culture of Cirebon This gives a different appeal for tourists to visit the city of Cirebon. For tourists who are new to the city of Cirebon is considered very difficult to get information and data about the locations you want to visit. Tour guides can be a solution for the tourists who are new to the area of Cirebon to provide general information that the travelers need , but the role of tourist guides may not be able to meet the needs and desires of the travelers.

Tourist guide application system designed in this Final Project -based Android platform. This application can provide information and be a signpost tourist locations you want to target. This application can function like a tour guide where the information given study covers the data 
culinary, tourist attractions, hotels, art, places of worship and transportation where such data is public information that travelers need.

The output results from the application of this tour guide can provide tourist information and a direction to an accuracy of A- GPS minimum error distance of 3 meters and a maximum error of 30 meters. Application in determining the speed of the user's position relies on a strong network signal and the circumstances surrounding conditions. This application could have been implemented on android smartphone.

Keywords: tour guide, android platform, cirebon, smartphone.

\section{PENDAHULUAN}

Aplikasi merupakan suatu wadah dalam seseorang untuk mengembangkan kreatifitasnya dalam berkarya. Salah satu yang sedang terkenal dalam pengembangannya adalah aplikasi android. Android mampu membuat berbagai macam aplikasi yang sangat berguna. Antara lain pemandu wisata. Di zaman sekarang wisatawan ingin dimudahkan untuk mengetahui suatu daerah yang ingin di tuju. Banyak diantaranya yang ingin berkunjung ke kota cirebon tetapi ragu karena belum mengetahui informasi yang jelas tentang kota tersebut.

Oleh karena itu, akan di buat sebuah aplikasi pemandu wisata dengan berbasis platform android. Aplikasi ini nantinya tidak hanya sekedar memberikan informasi saja tetapi menjadi penunjuk arah lokasi yang ingin dituju. Aplikasi ini dapat berfungsi layaknya pemandu wisata dimana informasi-informasi yang diberikan mancakup data restoran, tempat wisata, penginapan, tempat ibadah dan trasnportasi dimana data-data tersebut merupakan informasi umum yang dibutuhkan wisatawan.

\section{TEORI}

\subsection{KOTA CIREBON DAN POTENSI WISATA}

Cirebon dikenal dengan nama Kota Udang dan Kota Wali. Selain itu kota Cirebon disebut juga sebagai Caruban Nagari (penanda gunung Ceremai) dan Grage (Negeri Gede dalam bahasa jawa cirebon berarti kerajaan yang luas). Sebagai daerah pertemuan budaya Jawa dan Sunda sejak beberapa abad silam, masyarakat Cirebon biasa menggunakan dua bahasa, bahasa Sunda dan Jawa. Potensi Wisata di kota Cirebon sangat variatif, mulai dari budaya, kuliner, keagamaan, tempat wisata serta hotel-hotel yang bisa dikunjungi saat berada di kota Cirebon.

\subsection{ANDROID}

Android adalah sistem operasi yang berbasis Linux untuk telepon seluler seperti telepon pintar dan komputer tablet. Android menyediakan platform terbuka bagi para pengembang untuk menciptakan aplikasi mereka sendiri untuk digunakan oleh bermacam peranti bergerak. Awalnya, Google Inc. membeli Android Inc., pendatang baru yang membuat peranti lunak untuk ponsel. Kemudian untuk mengembangkan Android, dibentuklah Open Handset Alliance, konsorsium dari 34 perusahaan peranti keras, peranti lunak, dan telekomunikasi, termasuk Google, HTC, Intel, Motorola, Qualcomm, T-Mobile, dan Nvidia.

\section{Google API}

Google menyediakan berbagai API (Application Programming Interface) yang sangat berguna bagi pengembang web maupun aplikasi desktop untuk memanfaatkan berbagai fitur yang disediakan oleh Google seperti misalnya: AdSense, Search Engine, Translation maupun YouTube.. 


\section{JDK}

Java Development Kit (JDK) ini wajib hukumnya, karena Android merupakan aplikasi yang dibangun dengan menggunakan bahasa pemrograman Java. Untuk mendapatkan installer JDK bisa mengunduh / medownload langsung di situs resminya. Pilihlah installer JDK (java) yang sesuai dengan sistem operasi komputer kita. JDK yang bisa digunakan untuk membuat program Android adalah JDK 5 dan 6 atau versi terbarunya.

\section{SDK}

SDK adalah tools API (Aplication Programming Interface) yang digunakan untuk mulai mengembangkan aplikasi pada platform android menggunakan bahasa pemrograman Java. Android merupakan subset perangkat lunak untuk ponsel yang meliputi sistem operasi, middleware dan aplikasi kunci yang dikeluarkan oleh Google.

\section{Android Virtual Device}

Android Virtual Devices (AVD) adalah konfigurasi dari emulator sehingga kita dapat menjalankan perangkat Android sesuai model yang dipilih, misal Android 1.5 atau 2.2. Untuk dapat menjalankan emulator, Anda harus terlebih dahulu memiliki Android SDK.

\section{SQLite}

SQLite merupakan sebuah sistem manajemen basisdata relasional yang bersifat $A C I D$ compliant dan memiliki ukuran pustaka kode yang relatif kecil, ditulis dalam bahasa C. SQLite merupakan proyek yang bersifat public domain yang dikerjakan oleh D. Richard Hipp.

\section{SISTEM PEMANDU WISATA}

\subsection{Arsitektur Sistem}

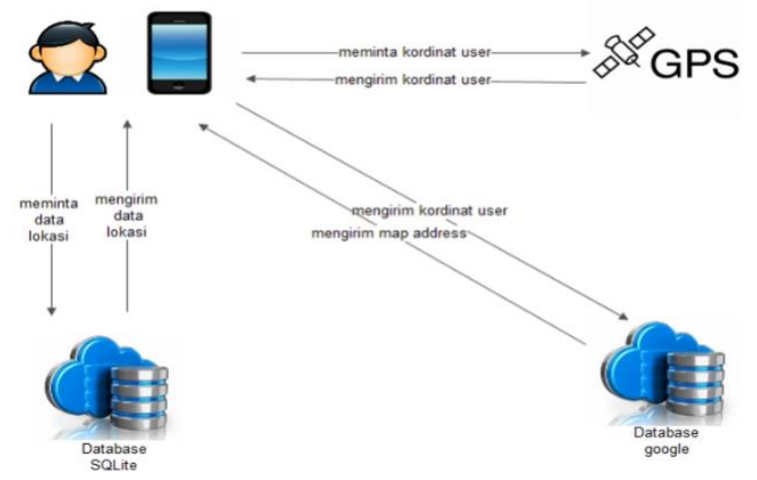

Gambar 1. Arsitektur Sistem

Gambar 1 di atas ini menggambarkan arsitektur sistem. Aplikasi pemandu wisata ini merupakan aplikasi yang berbasis location based service. Aplikasi ini memiliki data lokasi dan data peta yang berbeda tempat, untuk data lokasi dan informasi berada pada SQLite yang bersifat internal tetapi untuk data peta berada pada posisi Database google.

Pada saat memilih lokasi, sistem aplikasi akan meminta data kordinat lokasi pada database Sqlite dan GPS pada sistem akan merespon dengan mengirimkan kordinat dimana user berada, 
sesudah itu data kordinat lokasi dan user akan dikirimkan ke database google untuk mendapatkan alamat pada peta dan penunjuk arah.

\subsection{Use Case Diagram}

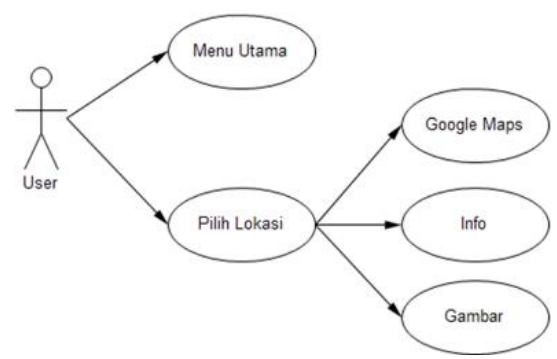

Gambar 2. Use Case Diagram

Use Case Diagram menggambarkan fungsionalitas yang diharapkan dari sebuah sistem dan sudut pandang pengguna sistem aplikasi ini. Gambar 2 di atas menjelaskan mengenai sistem yang dirancang pada android pada sisi pengguna. Tampilan utama terdiri dari 'menu utama' dan 'Pilih lokasi'. Pada menu Pilih lokasi, didalamnya terdapat submenu google maps yang digunakan sebagai tools melihat posisi user dan tempat wisata yang dituju, kemudian terdapat juga info mengenai gambar ataupun menu yang dipilih .

\subsection{Class Diagram}

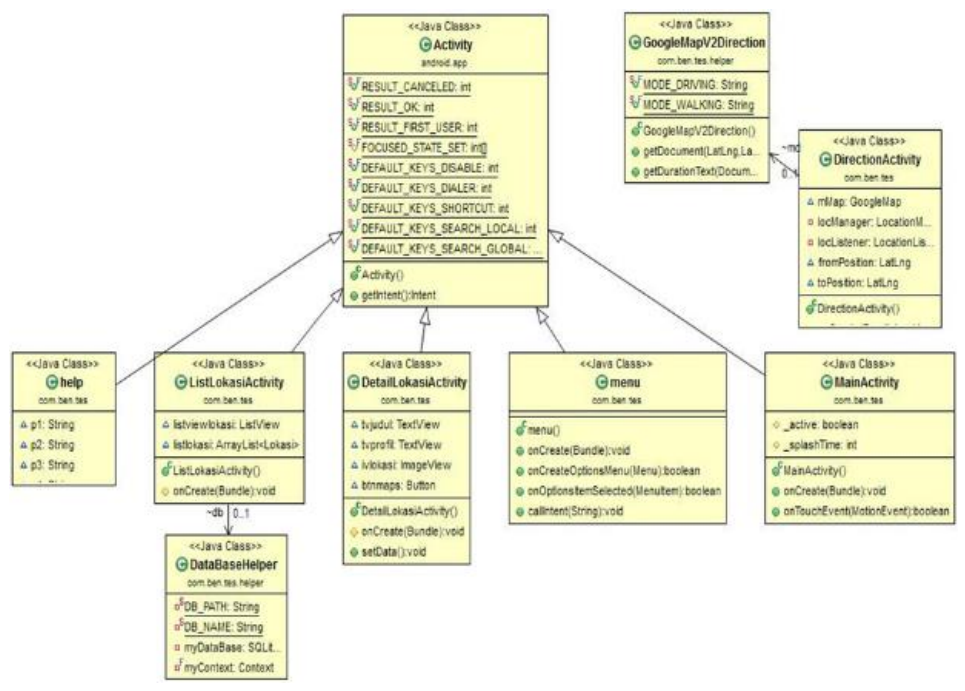

\section{Gambar 3. Class Diagram}

Gambar 3 merupakan diagram yang digunakan untuk menampilkan beberapa kelas serta paket yang ada di dalam sistem atau perangkat lunak. Diagram ini berupa tabel yang berisi nama kelas, atribut, dan method yang digunakan. Setiap tabel memiliki relasi masing - masing.

\subsection{Sequence Diagram}

Sequence diagram adalah diagram yang menggambarkan interaksi antar objek dan mengindikasikan komunikasi di antara objek-objek tersebut. Gambar 4 merupakan sequence diagram untuk melihat halaman utama, maka aplikasi akan meminta data. 


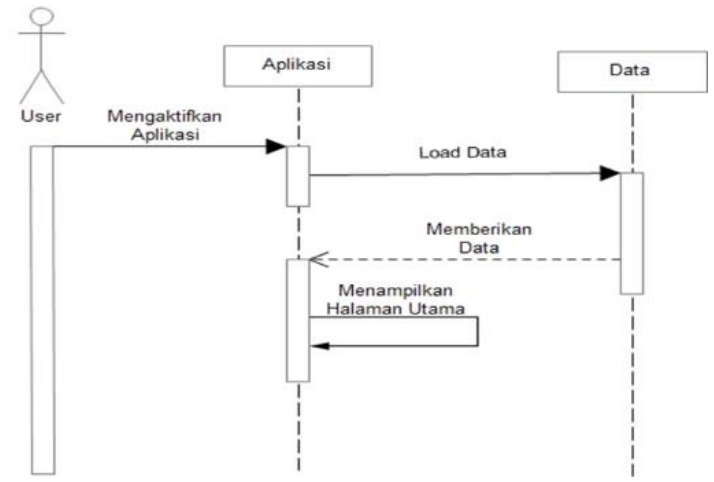

Gambar 4. Sequence Diagram

\subsection{Data Flow Diagram (DFD)}

DFD merupakan diagram yang menggunakan notasi - notasi untuk menggambarkan arus data sistem secara logika. DFD menggambarkan komponen - komponen sebuah sistem. Keuntungan menggunakan DFD adalah memudahkan pengguna yang kurang menguasai aplikasi android untuk mengerti sistem yang akan dikembangkan.

\section{Diagram Konteks}

Diagram konteks atau DFD level 0 ini merupakan gambaran dasar arus data aplikasi pemandu wisata kota cirebon yang nantinya akan didekomposisi menjadi sistem yang lebih detail. DFD level 0 ini terdapat dua entitas dan satu proses yang di tunjukan sebagai berikut :

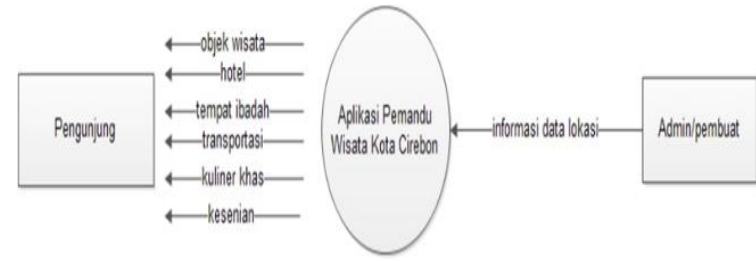

Gambar 5. DFD Konteks

Aplikasi sistem pemandu wisata hanya melibatkan satu tujuan data yaitu user. User dari aplikasi ini hanya dapat melihat daftar lokasi, informasi lokasi, peta lokasi dan rute perjalanan menuju objek wisata.

2. Diagram Level 1 proses lihat peta

Proses ini menerangkan alur dimana peta dapat dilihat oleh pengunjung.

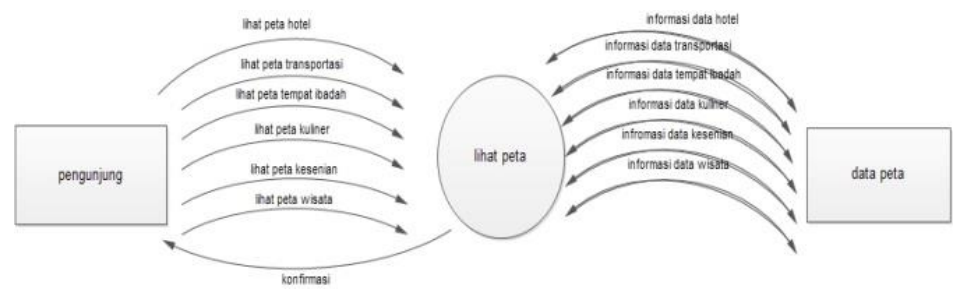

Gambar 6. DFD proses lihat peta 


\subsection{Entity Relationship Diagram}

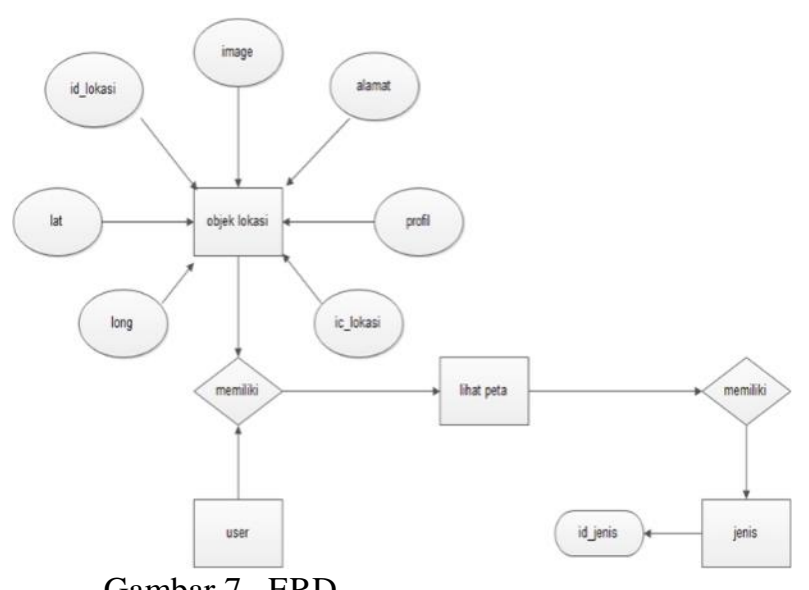

Gambar 7. ERD

Entity Relationship Diagram adalah salah satu metode pemodelan perangkat lunak yang biasanya digunakan dalam tahap analisis perancangan basis data. Diagram E- $\quad \mathrm{R}$ berupa model data konseptual yang merepresentasikan data dalam suatu organisasi.

Tahapan pembuatan E-R yaitu :

- mengidentifikasi dan menetapkan seluruh himpunan entitas yang akan terlibat

- menetukan atribut-atribut key dari masing-masing ensitas.

- mengidentifikasi dan menetapkan seluruh himpunan ensitas yang ada beserta foreign key.

- menetukan derajat/ kardinalitas relasi untuk setiap himpunan relasi.

- melengkapi himpunan entitas dan himpunan relasi dengan atribut-atribut deskriptif (non key).

\subsection{Database Sistem}

Sistem pada aplikasi ini membutuhkan database untuk memudahkan pengolahan data maupun mencari data-data yang akan dibutuhkan. Berikut adalah table yang terdapat dalam database.

1. id_lokasi : Berisi nomer data .

2. icon_lokasi $\quad$ : Berisi gambar ikon untuk list menu.

3. nama : Berisi penyimpanan nama tempat lokasi.

4. alamat : Berisi penyimpanan data alamat lokasi.

5. profil $\quad$ : Berisi data keterangan tentang lokasi.

6. image : Berisi data gambar lokasi.

7. jenis $\quad$ : Berisi data identitas untuk setiap menu.

8. latitude : Berisi data latitude tempat lokasi.

9. longitude $\quad$ : Berisi data longitude tempat lokasi. 


\subsection{Tampilan Aplikasi}

\subsubsection{Desain Layout}
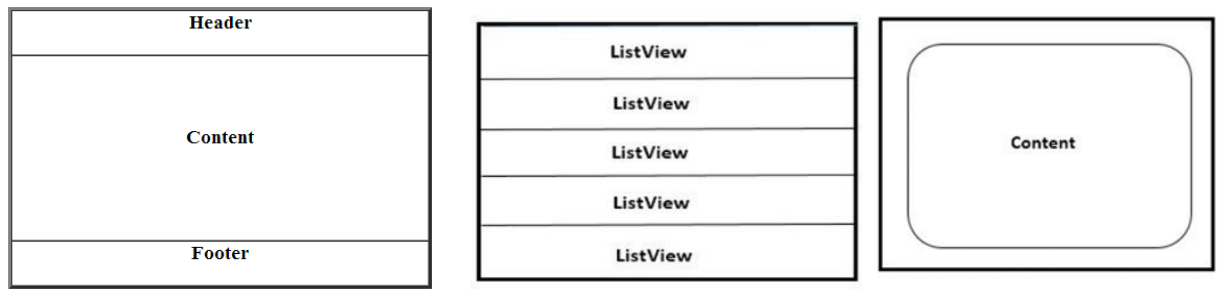

Gambar 8.Layout Utama, Listview, Detail Isi

\section{PENGUJIAN DAN HASIL}

\subsection{Pengujian Fungsional}

Pengujian fungsional dilakukan pada sistem masing-masing aplikasi untuk memastikan sistem berjalan sesuai dengan target yang telah ditentukan. Pada tahap ini, dilakukan pengujian dengan cara menjalankan semua panel menu yang terdapat pada aplikasi android.

\subsection{Pengujian Subyektif}

Pengujian dilakukan dengan tujuan untuk menentukan nilai subyektif yang dihasilkan, yaitu dengan cara memberikan kuisioner kepada 30 mahasiswa dan 15 pegawai dinas pariwisata kota cirebon. Sebelum mengisi kuisioner, dipersilahkan terlebih dahulu untuk mengakses aplikasi pemandu wisata. Kemudian memberikan penjelasan mengenai cara kerja, kelengkapan menu, serta fungsionalitas dan tujuan aplikasi. Berikut hasil pengujian :

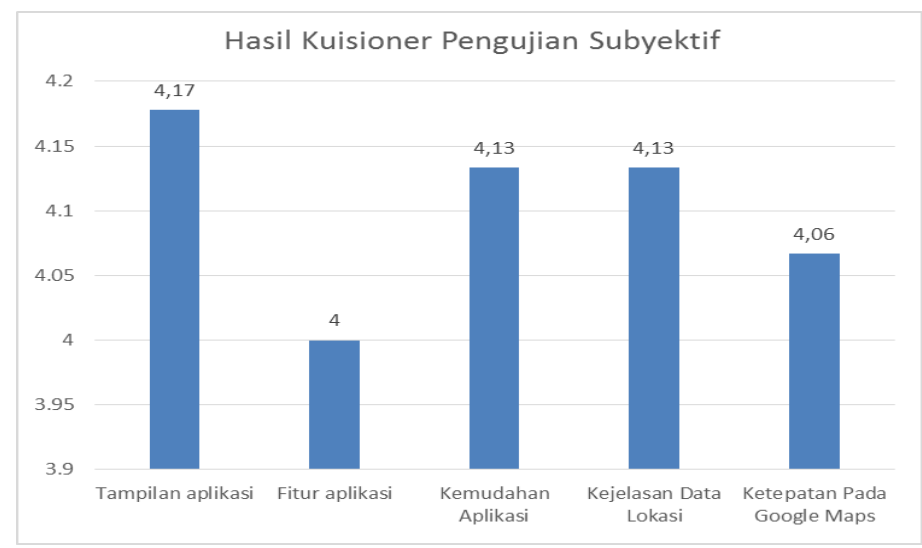

Gambar 9. Grafik Pengujian Subyektif

Dari hasil prosentase pengujian subyekifterlihat bahwa MOS didapat dengan cara :

$$
M O S=\frac{4,17+4+4,13+4,13+4,06}{5}=4,102
$$

Berdasarkan dari standar ITU-T mengenai perhitungan MOS secara subyektif dengan nilai MOS yang didapatkan yaitu 4,102 , maka performansi aplikasi pemandu wisata di kota cirebon berbasis android dapat dinyatakan baik. 


\subsection{Pengujian Akurasi GPS}

Prosedur pengujian GPS pada aplikasi pemandu wisata dimaksudkan untuk mengetahui kinerja dari aplikasi. Pengujian gps dilakukan dengan menginstal aplikasi ke smartphone. Aplikasi yang harus diinstal sebagai berikut :

1. GPS Test Aplikasi ini digunakan untuk mengetahui waktu tangkap dari GPS yang digunakan pada smartphone.

2. GPS Status

Aplikasi ini digunakan untuk mengetahui ketepatan jarak GPS pada suatu tempat lokasi tertentu.

\section{KESIMPULAN}

1. Pengujian fungsionalitas aplikasi sistem pemandu wisatadapat berjalan sesuai dengan yang diharapkan.

2. Pengujian akurasi A-GPS minimal error dengan jarak 3 meter dan maksimal eror 30 meter.

3. Kecepatan aplikasi dalam menentukan posisi pengguna bergantung pada kuat sinyal operator jaringan dan keadaan kondisi sekitar.

4. Aplikasi sudah sesuai yang diharapkan dan dinyatakan baik berdasar pada penilaian pengujian subyektif dengan nilai MOS $=4.116$.

5. Aplikasi dapat memberi petunjuk arah ke tempat lokasi sesuai yang diharapkan.

\section{DAFTAR PUSTAKA}

[1] Nazruddin Safaat. 2013. Berbagi Implementasi dan Pengembangan Aplikasi Mobile Berbasis Android. Bandung: Informatika.

[2] Nazruddin Safaat. 2012. Pemrograman Aplikasi Mobile Smartphone dan Tablet PC Berbasis Android. Bandung: Informatika.

[3] Agus Haryanto. 2014. Tutorial Android Menampilkan Lokasi GPS Pada Google Map, http://agusharyanto.net/wordpress/?p=480 ( diakses 23 Februari 2014 )

[4] Nur Amijaya. 2014. Membuat Aplikasi Android Rute GoogleMap V2 Direction Route GPS, http://cariprogram.blogspot.com/2013/05/android-googlemap-v2-direction-routedari-klik-marker-ke-lokasi-gps-mylocation.html?m=1 ( diakses 19 April 2014 )

[5] Stackoverflow. 2014, http://stackoverflow.com/ ( diakses 22 Juni 2014 ) 